\title{
Juventude nos musseques da literatura angolana: mesmos caminhos, outras trajetórias
}

Denise Cenci ${ }^{1}$

RESUMO: Este texto propõe um olhar para o percurso e os horizontes de dois jovens personagens moradores de musseques em obras literárias, dos períodos pré e pós independência em Angola: Zeca Santos, do livro Luuanda, publicado em 1963 por Luandino Vieira, e Nacib, do romance Predadores, publicado por Pepetela em 2004.

ABSTRACT: This paper proposes a look at the route and the horizons of two young characters living in musseques in literary works, before and after independence in Angola: Zeca Santos, of the Luuanda, book published in 1963, by Luandino Vieira, and Nacib, of the Predadores novel, published by Pepetela in 2004.

PAlaVRAS-CHAVE: Musseque; Juventude; Luandino Vieira, Pepetela; Angola

KEYWORDS : Musseque ; Youth; Luandino Vieira, Pepetela ; Angola

\section{Juventude e futuro}

Na obra $O$ Princípio Esperança, qualificada por Arno Münster como “fundadora de uma filosofia neomarxista do futuro" (MÜSTER, 1993, p.20), o filósofo Ernest Bloch desenvolve sua proposição da "utopia concreta", ideia radicalmente oposta à "utopia abstrata", pois ultrapassaria o que Marx denomina, no Manifesto Comunista, de “sublimação”. Nessa mesma linha, o pensador também inverteria a importância atribuída por Freud aos sonhos noturnos, ao procurar entender os produtos da imaginação social surgidos durante o estado de vigília - os sonhos diurnos - e a sua força "criadora" e "subversiva", no sentido de estes serem construtivos, anunciadores e antecipadores "de uma vontade futura mais firme e clara da emancipação, da reconstrução da sociedade segundo as ideias de igualdade, de dignidade humana, de fraternidade e de liberdade" (MÜNSTER, 1993, p.24-25).

Bloch estabelece uma ligação entre o futuro histórico e a antecipação do futuro utópico ao vislumbrar uma espécie de "sítio geométrico das coincidências entre a consciência emancipadora e os momentos revolucionários da história" (MÜNSTER, 1993, p.33). Une o conceito de "futuro" e de "criatividade" aos conceitos de "juventude"

\footnotetext{
${ }^{1}$ Mestranda na área de Estudos Comparados de Literaturas de Língua Portuguesa, da Faculdade de Filosofia, Letras e Ciências Humanas, na Universidade de São Paulo - FFLCH/USP.
}

Revista Crioula USP, $\mathrm{n}^{\circ}$ 17, junho de 2016 
e de "tempos de mudança", na perspectiva do surgimento das potencialidades utópicas que acabam por se transformar em prática, na qual as possibilidades de futuro se substancializam. O homem teria, assim, a capacidade de ir além do simples idealismo, teria o poder de deter-se à consciência proporcionada por seus sonhos diurnos, nos quais é possível agir racionalmente, para impactar também a realidade objetiva na condição de um "futuro autêntico", que extrapola o conteúdo trivial e banal pré-estabelecido no futuro de senso comum, considerado por ele como "futuro inautêntico".

Segundo o filósofo, a efetividade desse poder transformador dependeria de momentos de "rejuvenescimento da história", isto é, "épocas revolucionárias", que abrem espaço para uma nova sociedade, assim como se dá com a juventude que "se encontra subjetivamente no limiar de uma vida ainda não vivida até agora":

\begin{abstract}
A boa juventude segue as melodias que lhe cantam seus sonhos e seus livros...; ela espera a liberdade que está aqui diante dela. Ela é totalmente aspiração, totalmente desejo ao fugir à dupla prisão de sua imaturidade e dos constrangimentos que lhe impõem o mundo exterior... Se esta juventude coincide com uma época revolucionária, quer dizer, com um ponto de inflexão temporal...; ela compreende voluntariamente o que o 'sonho-para-frente' espera dela. (BLOCH, 1956, p.146 apud MÜNSTER, 1991, p.34)
\end{abstract}

No que diz respeito à juventude, mais especificamente, embora estudos atuais procurem não focalizá-la apenas na sua condição “de vir a ser”, ainda é a sua característica de transformação, de renovação e, principalmente, de possibilidade de melhoria futura que predominam.

Segundo a cientista social Regina Novaes: "Na sociedade moderna, embora haja variações dos limites de idade, a juventude é compreendida como um tempo de construção de identidades e de definição de projetos de futuro" (NOVAES, 2007, p.1). Em função disso, a juventude costuma ser a fase da vida mais marcada por ambivalências, entre as quais se destaca uma contraditória convivência entre a subordinação à família, à sociedade e, ao mesmo tempo, grandes expectativas de emancipação. A juventude, assim, tenderia a se configurar como uma espécie de "moratória social”, isto é, um período para que os indivíduos processem sua inserção nas diversas dimensões da vida social, como a responsabilidade com família própria, colocação no mundo do trabalho, exercício pleno de direitos e deveres de cidadania. Entretanto, é necessário considerar que:

[...] Em uma sociedade marcada por grandes distâncias sociais, são desiguais e diferentes as possibilidades de se viver a juventude como "moratória social", tempo de preparação. A condição juvenil é vivida de forma desigual e diversa em função da origem social; dos níveis de 
renda; das disparidades socioeconômicas entre campo e cidade; entre regiões [da mesma cidade], do mesmo país; entre países; entre continentes; entre hemisférios. [...] em cada tempo e lugar, fatores históricos, estruturais e conjunturais determinam as vulnerabilidades e potencialidades das juventudes. (NOVAES, 2007, p.1-2)

Há sempre uma imperiosa implicação contextual para que expectativas se concretizem e é a partir dessa perspectiva que se pretende analisar, neste texto, as aproximações e distanciamentos entre as histórias de dois jovens personagens moradores de musseques luandenses: Zeca, do conto Vavó Xíxi, do livro Luuanda, e Nacib, do romance Predadores, respectivamente, obras dos autores Luandino Vieira e Pepetela.

\section{Musseques como espaços ficcionais}

Os escritores Luandino Vieira e Pepetela são reconhecidos expoentes do sistema literário angolano. Suas biografias evidenciam a relação orgânica que estabeleceram com a história política e social de seu país. A militância atuante de ambos denota o compromisso que estabeleceram com seu povo no embate contra a dominação colonial portuguesa e com o ensejo por um projeto de nação livre para Angola. Suas obras reverberam um projeto literário pleno de engajamento, reflexão e denúncias, mas não por isso, menos transbordante em riqueza estética.

A literatura angolana engajada tomou para si a tarefa de desmascarar o opressivo colonialismo português que se escondia, mesmo diante da ONU, sob um discurso falacioso - em consonância com a política salazarista de então - dando-se ao direito de apregoar, por exemplo, que:

Em qualquer parcela do território nacional [incluindo as 'províncias de além-mar'] vigora o princípio da igualdade de direitos e de oportunidades de todos os habitantes, independentemente da sua 'raça'; a mestiçagem biológica e de culturas é considerada fonte de progresso e de desenvolvimento. As províncias de além-mar não são exploradas económica e financeiramente em favor das metropolitanas; aliás, nalguns territórios ultramarinos o crescimento económico chega a ser superior ao de Portugal continental. (CASTELO, 1999, p. 96).

No processo de desmascar o logro desse tipo de discurso, os modelos técnicoformais da literatura do colonizador foram negados em nome de uma proposta de nacionalismo, marcada pela linguagem ou pelas situações retratadas sob um ângulo diferente da relação entre colônia e metrópole. Conforme sinaliza Tania Macedo:

Se, no caso do Brasil, a natureza foi a forma de autoafirmação dos românticos no movimento de independência de Portugal, em África, será a cidade recriada, a partir de sua face africana e não mais europeia, a mola propulsora de uma literatura nacional. (MACEDO, 2002, p.70). 
A partir daí, à luz das ideias de Fanon, pode-se dizer que: a "cidade do colono" iluminada, asfaltada, sólida, toda de pedra e ferro - cede seu protagonismo no espaço ficcional angolano para a "cidade do colonizado": um "mundo sem intervalos, onde os homens estão uns sobre os outros, as casas umas sobre as outras. A cidade do colonizado, uma cidade faminta de pão, de carne, de sapatos, de carvão, de luz" (FANON, 1961, p.28).

Luanda, a capital de Angola, é uma cidade cercada por grandes bairros populares, que se assemelham às favelas brasileiras: os musseques. Sua origem quase se confunde com o surgimento da cidade propriamente dita e, como cada impulso das atividades econômicas é seguido por um aumento de migrantes na capital, os musseques foram se adaptando às novas configurações de espaço urbano, ao longo do tempo.

Os musseques tiveram seu primeiro grande crescimento com o fim da Segunda Guerra Mundial e, a partir do início da guerra civil em Angola, em 1975, tiveram um crescimento desordenado extremo, causado pela fuga da população interiorana, que, em busca de suposta segurança, estabeleceu-se nesses espaços de habitação mesmo que em total precariedade. Com o final da guerra civil, em 2002, houve uma onda de desenvolvimento e urbanização, porém não suficiente para mudar o cenário dos musseques que continuam densamente povoados e com grandes demandas por infraestrutura básica. Conforto, modernidade e luxo continuam sendo exclusividade das áreas de comércio e circulação da minoria que compõe a elite econômica do país.

Com o cuidado de não confundir o espaço ficcional com o real, verifica-se que o universo dos musseques constitui-se em ambientação privilegiada para narrativas focadas na problematização e na denúncia das injustiças sociais em Angola.

\section{O jovem Zeca Santos}

"Vavó Xíxi e seu neto Zeca Santos" é o primeiro dos três contos que compõem o livro Luuanda, escrito por Luandino Vieira, durante seus anos de cárcere. Com seu caráter inovador, o livro foi publicado em 1963 e vultosamente premiado em Angola e Portugal, causando polêmicas e represálias do regime salazarista por isso.

Em seu conjunto, a obra expõe as condições do colonialismo tardio em Angola: a miséria que assolava o cotidiano da maioria da população, a exploração econômica, as relações inter-raciais e a tensão social provocada pela presença do colonizador e suas 
práticas de opressão. Contudo, ao destacar as marcas da identidade nativa, o livro acena para resistência e para a esperança, especialmente representadas no conto de encerramento do livro, quando um ovo, após ser objeto de disputa de diferentes interesses - ora pessoais, ora institucionais -, é finalmente entregue à mulher grávida, portadora de uma especial promessa de futuro.

O jovem Zeca Santos protagoniza com sua avó as desventuras de uma relação intergeracional no seio da miséria e do abandono. No decorrer do conto, é possível saber que vavó Xíxi já foi Dona Cecília de Bastos Ferreira, mas foi destituída de seu prestígio com o declínio da elite crioula durante o século XX. Seu filho João Ferreira está preso, acusado de terrorismo, como tantos outros, restando, assim, à avó e ao neto apenas dividir a minúscula e precária cubata de um musseque, configuração perfeita da "cidade do colonizado, uma cidade acocorada, uma cidade ajoelhada, uma cidade acuada" (FANON, 1961, p.29).

Apesar de tantas privações, os traços que mais se sobressaem no jovem Zeca são justamente os que costumam marcar essa fase da vida: a interação com os colegas, a diversão, as conquistas amorosas e a preocupação com o consumo, principalmente relacionado a roupas e festas.

A presença perene e pulsante da fome, no decorrer de todo o conto, mantém uma atmosfera desconfortável, tensa e pesada que induz o leitor a julgar o comportamento do rapaz. A sabedoria de vida de sua avó, sempre a confrontá-lo com a necessidade de arranjar trabalho, de priorizar a compra de alimentos e de abdicar da vaidade, corrobora para ideia de que a futilidade de Zeca seria a grande responsável pela desgraça que os abate. Entretanto, considerando-se mais elementos presentes na narrativa, é possível enxergar uma complexidade maior dessas relações e do perfil do rapaz. Por exemplo ao notar que Zeca, mesmo com a sua curta experiência, não se abstém de procurar trabalho e vai pleitear oportunidade de se ocupar fazendo conferência de bomba de gasolina no comércio do branco "sô Souto", apenas em troca de comida, e sai de lá agredido física e moralmente, acusado de ladrão pelo homem que já fora considerado amigo de seu pai. Seguindo um anúncio de jornal, protagoniza outra ocasião infeliz, mas singular em sua expressividade:

\footnotetext{
Mas na entrada parou e o receio antigo encheu-lhe o coração. A grande porta de vidro olhava-lhe, deixava ver tudo lá dentro a brilhar, ameaçador. [...] mirou-se no vidro da porta e viu a camisa amarela florida, seu orgulho e vaidade das pequenas, amarrotada da chuva; as calças azuis velhas, muito lavadas, todas brancas nos joelhos; e sentiu bem o frio da pedra preta da entrada nos buracos dos sapatos rotos. Toda coragem tinha fugido nessa hora, as palavras que adiantara [...] com
} 
medo de sujar empurrou a porta de vidro e entrou, dirigiu-se ao grande balcão (VIEIRA, 2006, p.34).

Nem sua camisa, motivo de tanta censura pelo valor investido, foi capaz de diminuir o sentimento de insignificância e desajuste de Zeca diante do ambiente que encontrou. Via personificação, a porta ganha a capacidade de olhá-lo e evidencia a superioridade do objeto que rouba a condição de sujeito do garoto, desumanizando-o. $\mathrm{O}$ clima opressivo antecipa o resultado da entrevista: mais uma vez, Zeca sai de lá escorraçado sob a acusação de ser vagabundo e terrorista, desta feita, devido à sua aparência e ao lugar de origem ${ }^{2}$.

Ainda assim, persiste - esquálido e cambaleante de fome - aceita a mediação do amigo Maneco para conseguir uma vaga de carregador de sacos de cimento, trabalho pesado em troca de um valor irrisório.

Se por um lado, o orgulho de Zeca pode ser entendido como simples faceta de vaidade ou capricho, por exemplo quando revolta-se com a avó que lhe apresenta raízes de flor como alimento ou quando não se abre com o amigo Maneco e priva-se da refeição ofertada mesmo passando mal de fome; por outro, esse orgulho pode ser visto como prenúncio de questionamento à ordem instituída, por exemplo, quando menospreza a possibilidade de conseguir trabalho com o padre: "Ora possa! Serviço de varrer igreja, não é? Não Preciso!" e calou-se para evitar atrito com a avó que demonstra deferência à instituição: “Coisas da igreja, não fala assim!” (VIEIRA, 2006, p. 47).

A vida sentimental do jovem Zeca também é dramática, não apenas pela inexperiência da idade, mas novamente pelo agravante de suas condições sócioeconômicas, pois disputa as atenções de Delfina com o rival João Rosa, um mulato que, além de possuir seu próprio carro, ainda insinua ter poder de favorecimento à carreira da jovem operária. Apesar de Zeca ter demonstrado superioridade em uma briga com João e de receber sinais de interesse genuíno da moça, esta fica a escapar-lhe pelos dedos, já que o jovem não pode ser sincero com ela sobre a precariedade em que se encontra e, portanto, sobre a perspectiva de vida miserável que teria a lhe oferecer. O clímax da narrativa ocorre justamente durante seu encontro com Delfina, em local reservado entre a natureza. Zeca é dominado pela angústia ao se deparar com o caos que domina sua existência, zomba de seus desejos e anula suas ações. Junto a isso, o tormento provocado

\footnotetext{
${ }^{2}$ Que tanto pode ser identificado como o musseque, quanto o local de nascimento: a região do Catete, associada à subversividade, graças ao surgimento de lideranças importantes da luta anticolonial, como Agostinho Neto.
}

Revista Crioula USP, $\mathrm{n}^{\circ}$ 17, junho de 2016 
pela fome que o consome internamente há dias chega ao ápice e, desvairado, ele avança violentamente contra a garota, que o repele, hostiliza e agride no rosto. O rapaz literalmente vomita seu desgosto e segue derrotado para sua cubata, onde depois saberá por vavó que Delfina teria ido perguntar por ele.

A natureza viva, exultante e cheia de sonoridade aparece em diversas passagens do conto, entretanto, a atenção das personagens está sempre alheia ao espetáculo: "Mas vavó não sente esse barulho da vida à volta dela" (VIEIRA, 2006, p. 27). Apenas ao final da narrativa parece haver um ligeiro despertar, apesar do caos que persiste: "uma tristeza que enchia todo o corpo [de Zeca] e esses barulhos da vida [sinfonia de grilos, pássaros e rãs] lá fora fazia mais grande" (VIEIRA, 2006, p. 51)

O encerramento do conto é melancólico e triste, paira a atmosfera pesada de uma tortura que não cessa e que, certamente, não seria exclusividade de Zeca Santos, entre tantos jovens em musseques. A tragédia humana se fecha com o jorro de lágrimas sobre o rosto envelhecido do jovem 'abortado', a quem resta apenas o recurso infantil do choro:

\footnotetext{
Zeca voltou dentro e dobrou as calças muito bem, para aguentar os vincos. Depois, mais que ele podia fazer já, encostou a cabeça no ombro baixo de vavó Xíxi Hengele e desatou a chorar um choro de grandes soluços parecia era monandengue, a chorar lágrimas compridas e quentes que começaram a correr nos riscos teimosos as fomes já tinham posto na cara dele, de criança ainda (VIEIRA, 2006, p. 51)
}

A potencialidade e a obstinação do jovem Zeca não são suficientes para ultrapassar as barreiras da miséria e alcançar uma "consciência emancipadora". Em sua desgraça, resta-lhe apenas o minúsculo fio de esperança, na vaga possibilidade de rever Delfina.

\section{O jovem Nacib}

O romance Predadores, de Pepetela, foi publicado em 2005 e expõe a indignação de quem se depara com a nova burguesia que, ao final da guerra civil em Angola, ascendeu por meio de negócios ilícitos e relações escusas com o aparelhamento do Estado. Mas do que desilusão, o tom da narrativa é de denúncia, vinda de um narrador onisciente, petulante e provocador. Arbitrariamente, ele apresenta, em uma cronologia não linear, o período de 1992 a 2004 e mostra ao leitor as venturas e desventuras do corrupto sem limites que protagoniza a obra: Vladimiro Caposso. 
O personagem do jovem Nacib Germano de Castro é apresentado logo nos primeiros capítulos. Ele mora no musseque Catambor, relativamente próximo ao bairro nobre onde reside Vladimiro e sua família e é apaixonado por Mireille, filha caçula do soturno vilão.

Mesmo presente em apenas alguns dos vários capítulos da obra, é possível acompanhar a trajetória dos 15 aos 27 anos do garoto, filho de um carpinteiro e uma dona de casa, e vê-lo crescer como contraponto ao mau caráter protagonista do livro. A narração sobre Nacib divide-se principalmente entre as expectativas do tímido rapaz sobre o amor e os estudos. Ele é fascinado por mecânica e almeja ser engenheiro, mesmo em contrariedade aos planos do pai que ambiciona tê-lo como aprendiz em sua marcenaria para reforçar o orçamento doméstico e assumir-lhe o negócio futuramente.

No prisma romântico é criado certo suspense, explorando a formação moral de Mireille. Ela, por vezes, mostra-se espontânea na aproximação com o adolescente apesar das suas diferenças socioeconômicas: "mostrava tristeza por ficar tempos sem ver Nacib", "gostava de olhar e imaginar Nacib estudando e brincando embaixo do imbondeiro do Catambor" (PEPETELA, 2016, p.96). Por outras, apresenta grande afinidade com a funesta figura de seu pai, que a induzia à futilidade: "Mesmo quando conheceu o verdadeiro nome dele [Nacib] sempre o chamou voleur" (PEPETELA, 2016, p.95).

No âmbito dos estudos e da formação profissional, o rapaz avança vertiginosamente, sempre com o apoio e a mediação de seu padrinho Germano, caboverdiano dono de venda no musseque. Comunicativo e habilidoso, o padrinho dá mostras de sua capacidade argumentativa logo ao registrar a criança, garantindo à responsável pelo procedimento de que o nome Nacib seria legitimamente africano.

Para Nacib se formar engenheiro mecânico foi preciso 'estagiar' por muito tempo na oficina de Sô Mateus, na vizinhança: "Tinha sido conversa do padrinho de Nacib, o comerciante Germano, pois claro" (PEPETELA, 2016, p. 236), e até mesmo a espécie de "bolsa de estudos" recebida só foi possível por intermédio do padrinho que não apenas se encarregou de apaziguar os ânimos do pai carpinteiro inconformado, como desembolsou a quantia suficiente para cobrir a parte desfalcada do orçamento familiar do estudante: "fez ouvir sua voz com sotaque ilhéu em defesa dos sonhos do afilhado", o jovem correspondia agradecido pelos investimentos, "divertido pela maneira como o padrinho encostava sempre o pai nas cordas" (PEPETELA, 2016, p.238). Aos 20 anos estava formado com as notas mais altas que a faculdade conhecera e foi logo contratado por uma sociedade petrolífera que lhe pagou um curso de especialização na Califórnia. 
Se os tempos de faculdade já haviam mudado a rotina do rapaz com Mireille, durante o período em que esteve nos Estados Unidos, Nacib se envolveu com uma colega, a jovem loira Susan Dean: “Amantes, sim, mas dentro de casa. Porque na rua ou em sítios públicos nem de mão dadas andavam. Nem eles nem os outros [...] vocês são muito pudicos mesmo, dizia ele para Susan, deixam tudo para dentro de casa" (PEPETELA, 2016, p.250).

Embora sem compromisso: "Nunca falou a Susan de Mireille. E evitava pensar em Mireille. Mireille pertencia a Luanda e à vida dele, mas em Luanda. Estava agora na América, não dava para misturar" (PEPETELA, 2016, p.251). Apesar de seu distanciamento da filha de Vladimiro Caposso, ela permanece como uma espécie de obsessão romântica e incompreensível ao tímido rapaz.

Em 2003, Nacib volta para Luanda e para sua família cheia de orgulho. Mais experiente com "algum conhecimento do mundo de fora", mas sem deslumbramentos. “Ao voltar à terra, notou diferença nas coisas, nas pessoas, elas apareciam todos os dias. Não podia dizer que eram diferenças para melhor, mas parecia as pessoas estavam mais calmas, efeito da paz alcançada" (PEPETELA, 2016, p.260). Estava feliz de reencontrar sua gente e Kasseque, o amigo que fizera nas ruas, durante a adolescência, e fora ‘adotado' pela família, ocupando não mais um bueiro, mas seu pequeno cômodo contíguo ao quintal, para quem podia confidenciar suas inquietações sobre Mireille.

Enquanto a refinaria onde iria trabalhar não ficava pronta, assumiria seu posto em uma plataforma no mar. No ano seguinte, Mireille seguiu para Paris sob pretexto de estudar, mas tornou-se cada vez mais fútil e consumista, esbanjando a fortuna ilicitamente acumulada pelo pai. "Quando vinha a Luanda encontrava Nacib e recordava os velhos tempos, mas cada vez com menos entusiasmo" (PEPETELA, 2016, p.413), manipulava e desdenhava os sentimentos do rapaz, que considerava um tolo por continuar embasbacado diante da mulher que era para ele um verdadeiro enigma. Porém, "se enganava Mireille, pois Nacib estava preparado para enfrentar o mundo, só que de outra maneira. Nunca tinha estado preparado, isto sim, [...] à tremenda superioridade perante mim [...]. Demorou tanto tempo a descobrir, às vezes me custa acreditar [que ela andou só a gozar de mim] (PEPETELA, 2016, p.384).

No encerramento do romance, vê-se que até mesmo o lado mais frágil do rapaz passa por amadurecimento e busca por superação. É noite de Natal e ele divide a companhia do confidente Kasseque em frente à modesta casa da família, sob a qual ainda repousam as raízes do imbondeiro, o emblemático baobá, que precisou ser derrubado para 
que tivessem moradia no disputado espaço do musseque. $\mathrm{O}$ fim da narrativa ocorre com a entrega do presente de Nacib a Kasseque: todas as despesas pagas para que o amigo fizesse uma cirurgia corretiva em seu pênis, mutilado durante um procedimento precário de circuncisão na infância. Podia não haver certeza sobre a perenidade da paz, mas a cena é impregnada pelo clima de esperança.

Como se vê, é possível afirmar que a ficcional juventude angolana, representada nas figuras de Zeca Santos e Nacib, encontrou, no intervalo aproximado de meio século que separa as personagens, condições de vida muito diferentes em musseques.

A que parece, as privações e a fome extrema exauriram a capacidade de o alegre e encantador garoto Zeca Santos acessar a época revolucionária que o circundou. Seus poucos sonhos diurnos foram demasiadamente contaminados e desvirtuados pelos apelos do consumo. Sem fôlego para criticidade, restou-lhe ser objeto das ações alheias.

Já ao tímido Nacib, apesar das dificuldades, da fome meticulosamente fracionada pela mãe, foi possível desbravar seus caminhos, contornar obstáculos e manter firme sua obstinação, para tanto, contou com uma rede de solidariedade a lhe dar suporte. Se, a seu tempo, temperaturas mais amenas já dominavam o calor revolucionário, nem por isso cedeu aos apelos do sucesso capitalista a que teria acesso, preferiu o modelo do padrinho cabo-verdiano, a figura-chave de Germano, sempre disposto ao auxílio desinteressado e feliz pela contribuição para um futuro melhor. Seguindo seus passos, é sujeito de seus atos e ajuda a empoderar seus semelhantes.

Se a época colonial gerou inúmeras perdas, o período posterior à independência oficial do país também impõe seus desafios e a ficção parece sinalizar o caminho da solidariedade: buscar o que há de próprio e comum em cada cultura para aprender com as semelhanças e as diferenças para avançar e manter acesa a esperança em um futuro melhor a ser conquistado.

\section{Referências bibliográficas}

ABDALA, Benjamin Jr. De voos e ilhas: literaturas e comunitarismos. São Paulo: Ateliê, 2003.

CASTELO, Cláudia, 'O modo português de estar no mundo': o luso-tropicalismo e a ideologia colonial portuguesa: 1933-1961, Porto, Edições Afrontamento, 1999.

FANON, Frantz. Os condenados da terra. Tradução José Laurênio de Melo. Rio de Janeiro: Civilização Brasileira, 1968. 
MACEDO, Tania. Angola e Brasil: estudos comparados. São Paulo: Editora Arte e Ciência, 2003.

MÜNSTER, Arno. Ernst Bloch - Filosofia da Praxis e Utopia Concreta. São Paulo: Editora Unesp, 1993.

NOGUEIRA, Franco. As Nações Unidas e Portugal. Lisboa: Ática, 1961.

NOVAES, Regina C. R. ; RIBEIRO, E. ; SOUZA, P. L. Juventude: jogos de espelhos. In: Revista Ciência e Vida Sociologia Especial, São Paulo, p. 6 - 11, out. 2007.

Especial: Juventude Brasileira. Ano I. n 2. São Paulo: Escala: 2007. p. 6-15. Disponível em <http://www.antropologia.com.br/arti/colab/a38-rnovaes.pdf >. Acesso em julho de 2015.

PEPETELA. Predadores. Rio de Janeiro: Língua Geral, 2012.

VIEIRA, José Luandino. Vavó Xíxi e o seu neto Zeca Santos. In: Luuanda. São Paulo: Cia das Letras, 2006. 